\title{
Overuse of Oral Corticosteroids, Underuse of Inhaled Corticosteroids, and Implications for Biologic Therapy in Asthma
}

\author{
Katrien Eger ${ }^{a} \quad$ Marijke Amelink ${ }^{a}$ b Simone Hashimoto ${ }^{a} \quad$ Pieter-Paul Hekking $^{a}$ \\ Cristina Longo ${ }^{a}$ Elisabeth $\mathrm{H}$. Bel ${ }^{\mathrm{a}}$ \\ aDepartment of Respiratory Medicine, Amsterdam University Medical Center, University of Amsterdam, Amsterdam,

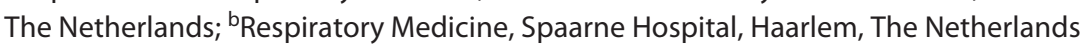

\section{Keywords}

Oral corticosteroid $\cdot$ Severe asthma $\cdot$ Biologic

\begin{abstract}
Background: Asthma patients using high cumulative doses of oral corticosteroids (OCSs) are at risk of serious adverse events and are increasingly being treated with steroid-sparing asthma biologics. However, it is unknown whether prescribing these expensive biologics is always justified. Objectives: This study aimed to (1) assess the prevalence of asthma patients using high cumulative doses of OCSs, (2) explore the role of suboptimal inhaler therapy, and (3) estimate the proportion of patients to whom asthma biologics might be prescribed unnecessarily. Methods: All adults ( $n=5,002$ ) with at least 1 prescription of high-dose inhaled corticosteroids ( $\geq 500-1,000 \mathrm{mcg} /$ day fluticasone-equivalent) and/or OCSs (GINA step 4-5) in 2010 were selected from a pharmacy database including 500,500 Dutch inhabitants, and sent questionnaires. Of 2,312 patients who returned questionnaires, 929 had asthma. We calculated the annual cumulative OCS dose and prescription fillings and checked inhaler technique in a sample of 60 patients. Patients estimated to have good adherence and inhaler proficiency who still re-
\end{abstract}

karger@karger.com www.karger.com/res

Karger

GOPEN ACCESS
(C) 2021 The Author(s)

Published by S. Karger AG, Basel

This is an Open Access article licensed under the Creative Commons Attribution-NonCommercial-4.0 International License (CC BY-NC) (http://www.karger.com/Services/OpenAccessLicense), applicable to the online version of the article only. Usage and distribution for commercial purposes requires written permission. quired high doses of OCSs ( $\geq 420 \mathrm{mg} /$ year) were considered candidates for initiating biologic treatment. Results: $29.5 \%$ of asthma patients on GINA 4-5 therapy used high doses of OCSs, of which $78.1 \%$ were likely to have poor therapy adherence or inadequate inhaler technique. Only $21.9 \%$ were considered definitive candidates for biologic therapy. Conclusion: High OCS use in Dutch GINA 4-5 asthma patients was common. However, in 4 out of 5 patients adherence to inhaled corticosteroid therapy and/or inhalation technique was considered suboptimal. Since optimizing inhaler therapy may reduce the need for OCSs, this should be mandatory before prescribing expensive steroid-sparing drugs.

@ 2021 The Author(s)
Published by S. Karger AG, Basel

\section{Introduction}

Many patients with severe or uncontrolled asthma use oral corticosteroids (OCSs) in addition to treatment with inhaled corticosteroids (ICS) and long-acting $\beta_{2}$-agonists (LABA) [1], either intermittently to treat exacerbations or chronically to maintain acceptable levels of asthma control [2]. Chronic or frequent use of OCS for asthma is known to be associated with a variety of serious and de- 
bilitating acute and chronic adverse effects [3], the incidence, type, and severity of which depend on the cumulative OCS dose used by the patient [4-6]. Even cumulative exposures as low as $0.5-1 \mathrm{~g}$ prednisolone equivalent have been reported to be associated with adverse outcomes [1]. Over the past 5 years, new biologics for severe asthma have become increasingly popular after studies had shown that these treatments can significantly reduce OCS courses in patients experiencing frequent asthma exacerbations and lower the OCS maintenance dose in OCS-dependent patients.

A major drawback of these biological treatments however, is the high cost compared to OCS tablets. It is therefore of the utmost importance that these expensive treatments are only prescribed to patients in whom all measures have been taken to reduce or prevent the use of OCS. In particular, it is important to ascertain whether patients have been prescribed sufficiently high doses of inhaled corticosteroids (ICS), whether they demonstrate optimal adherence to ICS and whether their inhalation technique is adequate. There is good reason for uncertainty in this respect, given the large "placebo" effect in the various phase 3 OCS tapering studies [7-9]. Therefore, the aim of the present study was to investigate whether asthma patients with high cumulative OCS use were adherent to ICS therapy and used their inhalers correctly, and to estimate the proportion of patients to whom asthma biologics might be prescribed unnecessarily.

\section{Material and Methods}

\section{Design and Study Population}

This is a cross-sectional study using data from a pharmacy database with prescription data from 65 community pharmacies in the Netherlands, including 500,500 patients from the general population. This database was also used in a previous study on the prevalence of severe asthma by Hekking et al. [10]. First, patients with at least 1 ICS prescription between January 1, 2011, and January 1, 2012 (study period), were identified. From these patients, patients with severe or uncontrolled asthma were identified. This included subjects with at least 1 prescription of high dose ICS ( $\geq 1,000$ mcg fluticasone-equivalent) or medium-high dose (500$1,000 \mathrm{mcg} /$ day fluticasone-equivalent) combined with maintenance OCS therapy ( $\geq 5 \mathrm{mg} /$ day prednisone equivalent for $\geq 6$ months in the previous year). All these patients $(n=5,002)$ were sent questionnaires, which included questions on demographics, medical history, medication consumption, smoking history, and asthma control. A total of 2,312 patients completed and returned questionnaires (response rate of 46.2\%). Table 1 shows characteristics of responders and nonresponders: mean age, ICS, and OCS dose were similar between responders and nonresponders; however, nonresponders were slightly younger and less often adherent to ICS than responders. Based on the data from the questionnaires, we selected adult patients ( $\geq 18$ years) with a diagnosis of asthma (i.e., self-reported diagnosis of "asthma" or self-reported diagnosis of "COPD" with a smoking history of $<10$ pack-years). Patients with other self-reported pulmonary diagnoses, such as sarcoidosis, cystic fibrosis, or bronchiectasis, were excluded.

\section{Outcomes}

"High cumulative OCS consumption" was defined as a cumulative dose of $\geq 420 \mathrm{mg}$ prednisone equivalent during the 1-year study period. We chose this cumulative cut-off dose because it corresponds to 2 OCS rescue courses per year $(30 \mathrm{mg}$ /day prednisone equivalent for 7 consecutive days), which is a criterion for the diagnosis of severe asthma by GINA and has shown to be associated with OCS-induced adverse effects $[5,11]$.

Good therapy adherence was defined as $\geq 80 \%$ fillings of ICS prescriptions during the study period. Inhaler technique was verified by pharmacists in a representative subsample of adherent patients, and adequate inhaler technique was defined as correct use (i.e., without making critical errors that would lead to insufficient drug reaching the airway) of all prescribed inhaler devices [11].

\section{Statistical Analysis}

We calculated the cumulative dose of prescribed OCS in our asthma patients and selected those who had used $\geq 420 \mathrm{mg}$ prednisone equivalent during the 1 -year study period. Then, we assessed the percentage of filled ICS prescriptions and classified patients into "adherent" and "non-adherent". Among the adherent patients who used high cumulative OCS doses, we computed the proportion of patients using their inhaler devices correctly. Standard errors and 95\% confidence intervals for proportions were computed for single proportions and were adjusted using the delta method for products of proportions. Approval for this study was obtained from the Medical Ethics Committee (MEC W11-064; NTR No. 3546).

\section{Results}

\section{Prevalence of Asthma Patients on High Cumulative}

Doses of OCSs

Of the patients with severe or uncontrolled asthma in the pharmacies database who returned questionnaires ( $n=2,312)$, asthma was diagnosed in $929(40.2 \%)$. Of these, 274 (29.5\%) patients were treated with high cumulative doses of OCS (shown in Fig. 1). These patients were mostly elderly females, with late-onset asthma, allergies, and recurrent exacerbations, taking median prednisone equivalent doses of $750 \mathrm{mg}$ per year (Table 2).

\section{Adherence and Inhaler Technique}

Of the 274 asthma patients using high dose OCS, 130 patients $(47.4 \%)$ were not adherent to ICS (prescription filling $<80 \%$ ). Among a random sample of 60 adherent patients, only $41.6 \%$ showed adequate inhaler technique (shown in Fig. 2). Thus, only $21.9 \%$ of patients were ad- 
Table 1. Patient characteristics of responders and nonresponders to the questionnaires

\begin{tabular}{|c|c|c|c|}
\hline & Responders $(n=2,312)$ & Nonresponders $(n=2,690)$ & $p$ value \\
\hline Age, year - med. IQR & $64(55-74)$ & $61(49-73)^{*}$ & 0.000 \\
\hline Male sex - \% & 44 & 43.5 & 0.720 \\
\hline Prescribed ICSs per day, $\mathrm{mcg}^{\dagger}-$ med. IQR & $1,000(600-1,000)$ & $1,000(600-1,000)$ & 0.059 \\
\hline Adherence to ICSs, \%\# - med.IQR & $82(49-107)$ & $67(39-99)^{*}$ & 0.000 \\
\hline Total OCS dose per year, $\mathrm{mg}^{\ddagger}-$ med. IQR & $400(210-826)$ & $360(210-840)$ & 0.329 \\
\hline
\end{tabular}

${ }^{\dagger}$ Inhaled corticosteroid dose is provided as fluticasone-equivalent. " Proportion of prescription that was filled. ${ }^{\ddagger}$ OCS dose is provided as prednisone equivalent. ${ }^{*} p$ value $<0.05$.

herent to ICS therapy and used their inhalers correctly, implying that $78.1 \%$ of patients with severe or uncontrolled asthma could be falsely labeled as candidates for biologic therapy.

\section{Discussion}

This study shows that in 2010-2011 about $30 \%$ of asthma patients with severe or uncontrolled asthma (7\% of the total asthma population) used high cumulative doses of OCS. Given the median prednisone equivalent dose of $750 \mathrm{mg} /$ year, these patients were at risk of serious adverse effects in the short and long term $[5,11]$. However, $78 \%$ of these patients were considered to have either poor therapy adherence or inadequate inhaler technique, or both, which may have contributed significantly to OCS overuse. Therefore, only $22 \%$ of the patients with high OCS use were regarded definite candidates for initiating therapy with biologics.

In our study, $30 \%$ of patients with severe or uncontrolled asthma were exposed to high cumulative doses of OCS. Other studies found slightly different prevalences. A recent systematic review on the use and health-related adverse effects of systemic corticosteroids in asthma elegantly summarized the findings of 129 studies addressing this topic [1]. For patients with severe or difficult-totreat asthma, short-term OCS was used in $46.3-92.6 \%$ of patients over a 1-year period, while chronic OCS use ranged from 33.2 to $65 \%$ in 5 studies of patients with moderate-to-severe or severe asthma. A study from Germany in asthma patients treated with high dose ICS/ LABA showed that $22 \%$ used $\geq 1$ OCS prescription in 1 year [12]. Another study from the United States found that $23 \%$ of GINA $4-5$ asthma patients could be classified as high OCS users at some point during an average follow-up of 40.8 months), with high OCS use defined as $\geq 450 \mathrm{mg}$ prednisone equivalent in a 90 -day period

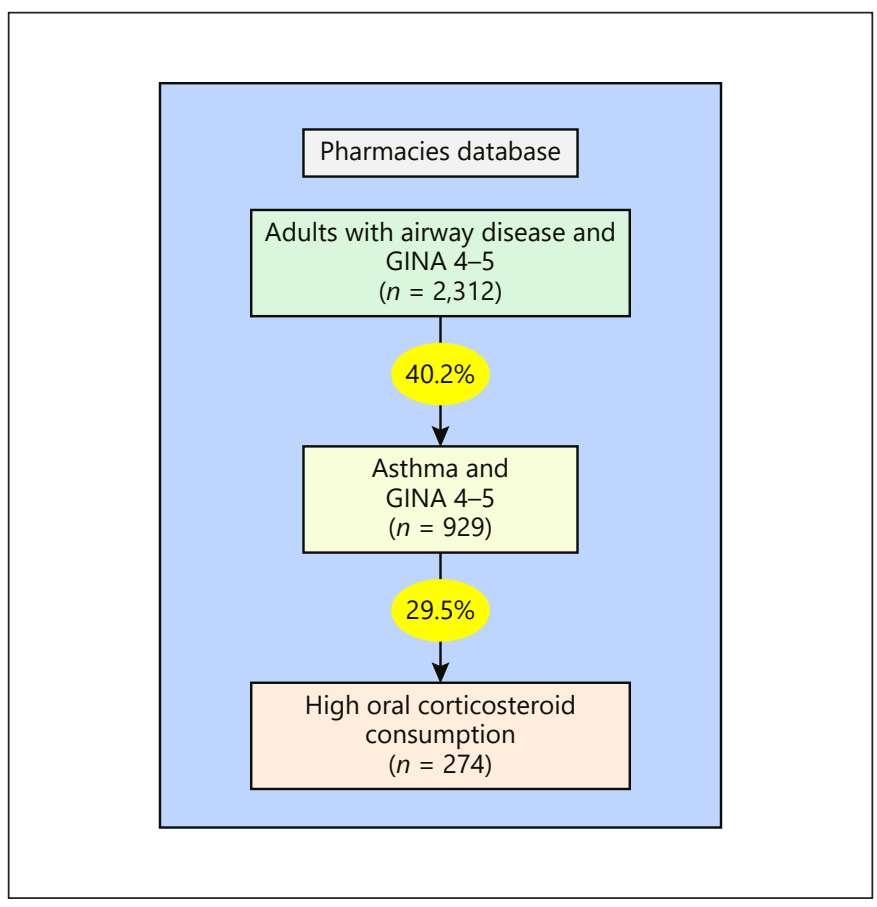

Fig. 1. Calculation of the prevalence of asthma patients on steps 4-5 who use high doses of OCSs. Results from the clinical questionnaires were combined with data on medication use to calculate prevalences of patients with severe or uncontrolled asthma, and the subset of patients using $\geq 420 \mathrm{mg}$ prednisone equivalent per year. GINA, Global Initiative for Asthma. OCS, oral corticosteroid.

[13]. An Australian study reported high OCS use defined as $\geq 1$ g prednisone equivalent/year in $10 \%$ of asthma patients on high dose ICS/LABA [14]. Such differences in reported prevalences of OCS using asthma patients are not surprising and may relate to differences in population, definitions of OCS use, or management strategies.

Our study shows that $47 \%$ of high OCS users were nonadherent to inhaler therapy, which is in line with pre- 
Table 2. Characteristics of patients with severe or uncontrolled asthma using high cumulative doses of OCSs
Fig. 2. Therapy adherence and inhalation technique in GINA 4-5 asthma patients who use high doses of OCSs. From a pharmacy database of 500,000 Dutch patients, 274 were identified with severe or uncontrolled asthma using high doses of OCSs. Of these $78.1 \%$ were considered nonadherent or having poor inhalator technique, only $21.9 \%$ were truly refractory to inhaled asthma therapy. Adherence rates were derived from prescription refills; inhalation technique was verified by pharmacists in a sample of 60 adherent patients. OCS, oral corticosteroid.

\begin{tabular}{|c|c|c|}
\hline \multirow{2}{*}{$\begin{array}{l}\text { Demographics } \\
\text { Age, year-med. IQR }\end{array}$} & \multicolumn{2}{|c|}{$N=274^{\dagger}$} \\
\hline & 67 & $59-78$ \\
\hline Male sex $-n \%$ & 84 & 30.7 \\
\hline BMI, kg/m² - med. IQR $(n=171)$ & 25 & $23-30$ \\
\hline Current smoker $-n \%(n=267)$ & 13 & 4.9 \\
\hline Pack-years $(P Y)^{\ddagger}-$ med. IQR $(n=271)$ & 0 & $0-1$ \\
\hline \multicolumn{3}{|l|}{ Asthma features } \\
\hline Allergy symptoms $s^{\S}-n \%(n=260)$ & 156 & 60 \\
\hline Nasal polyps $-n \%(n=262)$ & 74 & 28.2 \\
\hline \multicolumn{3}{|l|}{ Treating physician $(n=267)$} \\
\hline General practitioner $-n \%$ & 66 & 24.7 \\
\hline Pulmonologist - $n \%$ & 201 & 75.3 \\
\hline \multicolumn{3}{|l|}{ Asthma control } \\
\hline ACQ-6 scoreף - med. IQR & 1.67 & $0.83-2.52$ \\
\hline \multicolumn{3}{|l|}{ Rescue OCS courses in past year } \\
\hline None $-n \%$ & 59 & 21.5 \\
\hline $1-2$ courses $-n \%$ & 106 & 38.7 \\
\hline 3 or more $-n \%$ & 109 & 39.8 \\
\hline \multicolumn{3}{|l|}{ Hospital admission for asthma in past year } \\
\hline None $-n \%$ & 197 & 71.9 \\
\hline $1-2$ admissions $-n \%$ & 57 & 20.8 \\
\hline 3 or more $-n \%$ & 20 & 7.3 \\
\hline \multicolumn{3}{|l|}{ Medication } \\
\hline Prescribed ICSs per day, mcg $^{\dagger \dagger}-$ med. IQR & 750 & $600-1,000$ \\
\hline Total prescribed oral corticosteroid dose per year, mg ${ }^{\ddagger \neq}-$ med. IQR & 750 & $510-1,650$ \\
\hline \multicolumn{3}{|c|}{$\begin{array}{l}\text { OCS, oral corticosteroid; ICS, inhaled corticosteroid. ACQ- } 6 \text { is the } 6 \text {-item Asthma Control } \\
\text { Questionnaire. }{ }^{\dagger} \text { Unless otherwise stated. }{ }^{\ddagger} 1 \text { pack year equals smoking of } 20 \text { cigarettes per } \\
\text { day during } 1 \text { year. }{ }^{\S} \text { Self-reported allergy to common inhaled allergens. }{ }^{\dagger \dagger} \text { ICS dose is pro- } \\
\text { vided as fluticasone-equivalent. }{ }^{\text {}} \text { Oral corticosteroid dose is provided as prednisone equiv- } \\
\text { alent. }\end{array}$} \\
\hline
\end{tabular}

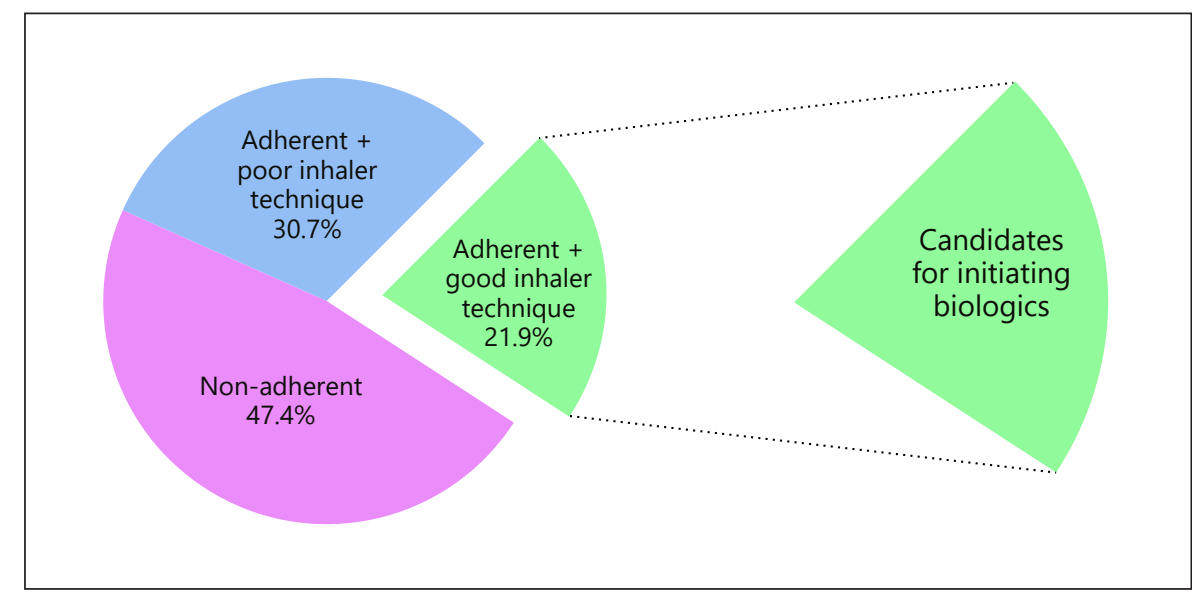

vious reports showing showed similar disappointing rates, ranging from 42.5 to $65 \%$ [14-18]. Still, when checking inhaler proficiency in a representative sample of 60 adherent patients, more than half (60\%) were not able to use their inadequate inhaler correctly. Our finding of

Oral Corticosteroid Overuse in Severe Asthma poor inhaler technique is slightly lower than that from another recent study, in which critical inhaler technique mistakes were made in $70.3-86.6 \%$ of patients, depending on the inhaler device [11]. Last, our findings of $21.9 \%$ of patients being adherent and showing good inhaler tech- 
nique are consistent with the findings of another study showing that after an educational program of adherence and inhaler technique assessment, $27 \%$ of patients were truly refractory to therapy [19]. Overall, the observations in this study are important and clinically relevant, since it shows that in the majority of patients with severe asthma and high OCS use, at least 1 major modifiable factor can be identified that is likely to contribute to overuse of OCS which should be addressed before biologic therapy is considered in these patients.

The present study may have some limitations. First, the prevalence of high OCS users may have been underestimated for several reasons such as differences between responders and nonresponders to the questionnaires in adherence rates (lower in nonresponders) or other factors such as ongoing allergen exposure or uncontrolled comorbidities that were not taken into account. Second, our study was confined to the Dutch population, which may limit generalizability to other countries. And lastly, it is likely that OCS overuse is not restricted to patients with severe or uncontrolled asthma and also occurs in patients with less severe disease (e.g., GINA step 2-3) [1].

The strengths of this study are the large number of representative patients in the pharmacy database, the availability of clinical data derived from questionnaires, the availability of therapy adherence data, as well as the assessment of inhaler technique in a representative sample. Further, we were able to compute the cumulative dose of OCS therapy, which increased the accuracy of assessing the prevalence of patients excessively exposed to OCS and thus the population at risk for adverse side effects.

The possible reasons for OCS overuse in asthma patients are numerous. However, the most obvious and common reason is that many patients are under-treated with ICS/LABA, due to nonadherence to treatment or inadequate inhaler technique $[18,20]$. These patients are likely to require much less OCS if these factors were addressed. This is also illustrated by the large placebo effect observed in many controlled trials with oral steroidsparing biologics [7-9], Another reason of OCS overuse may be that these drugs are prescribed inappropriately for nonsteroid responsive conditions, including nontype 2 asthma, remodeled airways without active inflammation, or symptoms of comorbidities such as obesity, dysfunctional breathing, or bronchiectasis [21, 22]. Finally, some asthma patients may still use high cumulative doses of OCS because they are not recognized as high OCS users and are not referred to an asthma specialist. This is illustrated by the present study in which 1 in 4 patients with high OCS use was not monitored by a pulmonologist.

This study has important clinical implications. Patients who require high doses of OCS, either recurrent short courses or maintenance treatment, should always undergo a thorough clinical assessment, including an evaluation of adherence, inhaler technique, exposures to asthma triggers, and comorbidities [23-25]. If not done before, they should also undergo trial therapy with long-acting muscarinic antagonist or macrolides. Patients that are still refractory to therapy despite all these measures and who show clear signs of type 2 airway inflammation should be eligible for biologic therapy. This also includes chronically poor adherent patients who carry a very large burden of the disease (e.g., patients admitted in ICU, frequently admitted in the ward, or already suffering from very severe OCS-induced side effects) to whom all efforts available have been provided.

In summary, our study shows that almost one-third of GINA step 4-5 asthma patients in the Netherlands were exposed to high and potentially harmful cumulative doses of OCS in the prebiologic era. Eighty percent of these patients were considered to be nonadherent to inhaled asthma treatment or to have inadequate inhaler proficiency, 2 major factors that are known to contribute to poor asthma control and could be improved. OCS use could probably have been reduced in a proportion of patients if these issues had been addressed. Physicians should therefore not prescribe expensive biologics to patients with high OCS use until they have thoroughly verified that inhaled ICS therapy is being used in an adequate and appropriate manner.

\section{Acknowledgement}

We would like to thank all patients who participated in this study by returning the questionnaires.

\section{Statement of Ethics}

This research was conducted ethically in accordance with the World Medical Association Declaration of Helsinki. Approval for this study was obtained from the Medical Ethics Committee (MEC W11-064; NTR No. 3546). The analysis was performed with anonymized data. Written informed consent was obtained from patients undergoing a check of their inhalation technique. 


\section{Conflict of Interest Statement}

K.E., M.A., S.H., P.W.H., and C.L. have no conflicts of interest to declare. E.H.B. reports grants and personal fees from AstraZeneca, G.S.K., Novartis, Sanofi/Regeneron, Teva, Chiesi, and Sterna outside the submitted work.

\section{Funding Sources}

The collection of pharmacy data was sponsored by Novartis Pharma. The sponsor had no role in the preparation of the data or the manuscript.

\section{Author Contributions}

M.A., P.W.H., and E.H.B. participated in the collection of data. E.H.B., K.E., M.A., S.H., P.W.H., and C.L. were involved in the designing of the study, analysis of data, writing, and reviewing the manuscript.

\section{Data Availability Statement}

All data generated or analyzed during this study are included in this article. Further enquiries can be directed to the corresponding author.

\section{References}

1 Bleecker ER, Menzies-Gow AN, Price DB, Bourdin A, Sweet S, Martin AL, et al. Systematic literature review of systemic corticosteroid use for asthma management. Am J Respir Crit Care Med. 2020 Feb 1;201(3):276-93.

2 Pavord ID. Oral corticosteroid-dependent asthma: current knowledge and future needs. Curr Opin Pulm Med. 2019 Jan;25(1):51-8.

3 Volmer T, Effenberger T, Trautner C, Buhl R. Consequences of long-term oral corticosteroid therapy and its side-effects in severe asthma in adults: a focused review of the impact data in the literature. Eur Respir J. 2018;52(4) 1800703.

4 Sullivan PW, Ghushchyan VH, Globe G, Schatz M. Oral corticosteroid exposure and adverse effects in asthmatic patients. J Allergy Clin Immunol. 2018;141(1):110-6.e7.

5 Price DB, Trudo F, Voorham J, Xu X, Kerkhof M, Ling Zhi Jie J, et al. Adverse outcomes from initiation of systemic corticosteroids for asthma: long-term observational study. J Asthma Allergy. 2018;11:193-204.

6 Chalitsios CV, Shaw DE, Mckeever TM. Risk of osteoporosis and fragility fractures in asthma due to oral and inhaled corticosteroids : two population-based nested case-control studies. Thorax. 2021 Jan;76(1):21-8.

7 Bleecker ER, FitzGerald JM, Chanez P, Papi A, Weinsteine SF, Barker P, et al. Efficacy and safety of benralizumab for patients with severe asthma uncontrolled with high-dosage inhaled corticosteroids and long-acting $\beta 2$ agonists (SIROCCO): a randomised, multicentre, placebo-controlled phase 3 trial. Lancet. 2016;388(10056):2115-27.

8 Pavord ID, Korn S, Howarth P, Bleecker ER, Buhl R, Keene ON, et al. Mepolizumab for severe eosinophilic asthma (DREAM): a multicentre, double-blind, placebo-controlled trial. Lancet. 2012;380(9842):651-9.
9 Castro M, Corren J, Pavord ID, Maspero J, Wenzel S, Rabe KF, et al. Dupilumab efficacy and safety in moderate-to-severe uncontrolled asthma. N Engl J Med. 2018;378(26): 2486-96.

10 Hekking PP, Wener RR, Amelink M, Zwinderman AH, Bouvy ML, Bel EH. The prevalence of severe refractory asthma. J Allergy Clin Immunol. 2015;135(4):896-902.

11 Price DB, Román-Rodríguez M, McQueen RB, Bosnic-Anticevich S, Carter V, GruffyddJones $\mathrm{K}$, et al. Inhaler errors in the CRITIKAL Study: type, frequency, and association with asthma outcomes. J Allergy Clin Immunol Pract. 2017;5(4):1071-81.e9.

12 Taube C, Bramlage P, Hofer A, Anderson D. Prevalence of oral corticosteroid use in the German severe asthma population. ERJ Open Res. 2019;5(4).

13 Tran TN, MacLachlan S, Hicks W, Liu J, Chung Y, Zangrilli J, et al. Oral corticosteroid treatment patterns of patients in the United States with persistent asthma. J Allergy Clin Immunol Pract.2021 Jan;9(1):338-46.e3.

14 Hew M, McDonald VM, Bardin PG, Chung LP, Farah CS, Barnard A, et al. Cumulative dispensing of high oral corticosteroid doses for treating asthma in Australia. Med J Aust. 2020;213(7):316-20.

15 Murphy AC, Proeschal A, Brightling CE, Wardlaw AJ, Pavord I, Bradding P, et al. The relationship between clinical outcomes and medication adherence in difficult-to-control asthma. Thorax. 2012;67(8):751-3.

16 Gamble J, Stevenson M, McClean E, Heaney LG. The prevalence of nonadherence in difficult asthma. Am J Respir Crit Care Med. 2009;180(9):817-22.
17 von Bülow A, Backer V, Bodtger U, Søes-Petersen NU, Vest S, Steffensen I, et al. Differentiation of adult severe asthma from difficultto-treat asthma: outcomes of a systematic assessment protocol. Respir Med. 2018;145: 41-7.

18 Engelkes M, Janssens HM, de Jongste JC, Sturkenboom MC, Verhamme KM. Medication adherence and the risk of severe asthma exacerbations: a systematic review. Eur Respir J. 2015;45(2):396-407.

19 Sulaiman I, Greene G, MacHale E, Seheult J, Mokoka M, D’Arcy S, et al. A randomised clinical trial of feedback on inhaler adherence and technique in patients with severe uncontrolled asthma. Eur Respir J. 2018;51:1701126.

20 Garcia-Cardenas V, Armour C, Benrimoj SI, Martinez-Martinez F, Rotta I, Fernandez-Llimos F. Pharmacists' interventions on clinical asthma outcomes: a systematic review. Eur Respir J. 2016;47(4):1134-43.

21 Fahy JV. Type 2 inflammation in asthma: present in most, absent in many. Nat Rev Immunol. 2015;15(1):57-65.

22 Kaur R, Chupp G. Phenotypes and endotypes of adult asthma: moving toward precision medicine. J Allergy Clin Immunol. 2019; 144(1):1-2

23 McBrien CN, Menzies-Gow A. Time to FOCUS on oral corticosteroid stewardship in asthma management. Respirology. 2019; 24(4):304-5

24 Heaney LG, Busby J, Bradding P, Chaudhuri R, Mansur AH, Niven R, et al. Medical research council UK refractory asthma stratification programme (RASP-UK). Remotely monitored therapy and nitric oxide suppression identifies nonadherence in severe asthma. Am J Respir Crit Care Med. 2019 Feb 15; 199(4):454-64.

25 Ryan D, Heatley H, Heaney LG, Jackson DJ, Pfeffer PE, Busby J, et al. Potential severe asthma hidden in UK primary care. J Allergy Clin Immunol Pract. 2021 Apr;9(4):1612-e9. 